\title{
Efeitos do câmbio, juros e do crescimento mundial sobre as exportações da indústria brasileira
}

\author{
Luciano Nakabashi* \\ Marcio José Vargas da Cruz \\ Fábio Dória Scatolin ${ }^{* *}$
}

\begin{abstract}
RESUMO - O objetivo do presente artigo é analisar a relação do câmbio real, dos juros e do crescimento mundial sobre total das exportações brasileiras e sua composição. As três variáveis acima mencionadas afetam não somente o montante exportado por um país, mas também sua composição. Adicionalmente, a estrutura dessa composição possui efeitos na própria dinâmica das exportações. O setor exportador, por sua vez, tem um papel chave sobre o desempenho da economia brasileira na medida em que as restrições externas ao crescimento tem se apresentado como um problema recorrente nos últimos 25 anos, o que ajuda a explicar o seu fraco desempenho. Essa importante relação entre as duas variáveis justifica um estudo mais detalhado da composição do setor exportador da economia brasileira.
\end{abstract}

Palavras-chave: Mudança estrutural. Exportações. Taxa de câmbio. Taxa de juros.

\section{INTRODUÇÃO}

O objetivo do presente artigo é analisar a relação das taxas de câmbio, de juros e do crescimento mundial sobre total das exportações brasileiras e de sua composição. A importância de tal análise se deve à relação existente entre a composição do setor exportador e o seu dinamismo, ou seja, na elasticidade renda deste.

O setor exportador, por sua vez, tem um papel chave sobre o desempenho da economia brasileira na medida em que as restrições externas tem se apresentado como um problema recorrente nos últimos 25 anos, ajudando a explicar seu fraco desempenho.

A teoria pós-keynesiana serve de base para a argumentação de que o desempenho do setor exportador é essencial na determinação do crescimento, no longo prazo, devido ao seu

\footnotetext{
* Doutor em Economia pelo CEDEPLAR/UFMG. Professor do Departamento de Economia da Universidade Federal do Paraná (UFPR). Endereço eletrônico: luciano.nakabashi@ufpr.br.

** Mestre em Economia pela Universidade Federal do Paraná. Professor do Departamento de Economia da Universidade Federal do Paraná (UFPR). Endereço eletrônico: marciocruz@ufpr.br.

*** Doutor em Economia pela University of London. Professor do Departamento de Economia da Universidade Federal do Paraná (UFPR). Endereço eletrônico: scatolin@ufpr.br.
} 
duplo papel de estímulo à demanda pelos produtos domésticos e de relaxamento da restrição externa ao crescimento.

A relação entre crescimento econômico, restrição externa e exportações tem como base teórica o modelo desenvolvido por THIRLWALL (1979), em que as restrições externas ao crescimento possuem um papel fundamental neste processo. Nesse modelo, as elasticidades renda das importações e das exportações são elementos chaves para um bom desempenho econômico de longo prazo (MCCOMBIE e ROBERTS, 2002).

Adicionalmente, o desempenho do setor exportador tem um impacto direto sobre a estrutura produtiva de um país ao determinar os setores mais competitivos da mesma e, portanto, com maiores potenciais de crescimento. $\mathrm{Na}$ medida em que a estrutura produtiva de uma economia é importante na determinação do seu dinamismo, esse fator passa a ser crucial no crescimento econômico de longo prazo.

O papel do câmbio é relevante, pois altera o valor total das exportações ao induzir mudanças nos preços relativos dos bens domésticos em relação aos estrangeiros, além de ser importante na determinação da estrutura produtiva da economia ao passo em que alguns segmentos e setores são mais sensíveis à competitividade via preços. A taxa de juros doméstica atua sobre a estrutura produtiva, pois os setores e segmentos compostos por grandes empresas têm maior facilidade de financiamento externo. Desse modo, eles são menos sensíveis a variações da taxa de juros doméstica. O crescimento da renda mundial, por sua vez, tende a favorecer mais a exportação dos bens com maiores elasticidades renda.

Além da presente introdução, o presente estudo se encontra estruturado da seguinte forma: na seção 2 é apresentada a metodologia a ser utilizada na análise empírica e as fontes dos dados. Finalmente, na seção subseqüente, os resultados empíricos são apresentados e discutidos.

\section{METODOLOGIA E FONTE DOS DADOS}

A análise é feita com dados mensais e o período vai de janeiro de 1996 a fevereiro de 2008, data a partir da qual os dados detalhados das exportações estão disponibilizados pela Secretaria de Comércio Exterior (SECEX/MDIC). A proxy para a taxa de juros real é a Selic fixada pelo Comitê de Política Monetária (COPOM) descontada pela expectativa média de inflação (IPCA) para 12 meses, com ambas as séries provenientes do Boletim do Banco Central do Brasil. 
Os dados da taxa de câmbio (taxa de câmbio efetiva real - IPA-IT-Exportações) são oriundos do IPEA. As séries das exportações mensais classificadas de acordo com o nível de intensidade dos recursos foram deflacionadas pelo IPCA do Instituto Brasileiro de Geografia e Estatística (IBGE).

Os dados do PIB dos Estados Unidos estão em valores reais e foram utilizados como proxy para a renda mundial ( $Z$ na equação (1)), pois os dados desta estão disponíveis apenas anualmente. A fonte é o Bureau of Economic Analysis do U.S. Department of Commerce. Como os dados do PIB americano estão disponíveis apenas trimestralmente, foi considerada uma taxa de crescimento constante a cada três meses para que os dados fossem transformados em uma série mensal.

A análise empírica foi realizada através da utilização de gráficos e regressões econométricas utilizando o método de defasagens distribuídas para analisar o impacto das taxas de câmbio, juros e crescimento dos EUA na participação relativa das exportações de cada um dos cinco sub-setores industriais no total exportado pela indústria.

A análise de regressão foi realizada com variáveis defasadas. A inclusão destas foi feita, pois existe certa defasagem entre mudanças no câmbio, juros e na renda dos parceiros comerciais sobre as exportações. Foram realizados testes para verificar se as séries são estacionárias para evitar problemas de correlação espúria entre as variáveis. O critério para seleção de defasagens, da presença de uma constante e tendência no teste de Dickey-Fuller foi o de Akaike.

De fato, a única série que não se rejeita a presença de raiz unitária é a da taxa de crescimento das exportações baseadas em diferenciação. No entanto, como as demais são estacionárias, não haveria problema de correlação espúria nos resultados da regressão. Assim, optou-se por estimar a regressão utilizando também essa série como variável dependente.

Foram feitos testes de normalidade dos resíduos do Stata, sendo estes baseados em D'AGOSTINE, BELANGER e D’AGOSTINE JR., (1990 apud PARK, 2003)' de heterocedasticidade, autocorrelação e multicolinearidade. Os problemas encontrados foram corrigidos com os métodos adequados, como exposto na próxima seção.

\section{RESULTADOS}

Realizados de acordo com a análise gráfica.

\footnotetext{
${ }^{1}$ O teste é construído através de uma medida de assimetria e outra de curtose da distribuição dos resíduos.
} 


\subsection{ANÁLISE GRÁFICA}

De acordo com os dados apresentados no Gráfico 1, a apreciação do câmbio está em curso desde o final de 2002. As duas séries mostram que junho de 2008 foi o mês que apresentou maior apreciação do câmbio desde o início do plano real. Mesmo que alguns analistas digam que tal processo se deve, em grande medida, à depreciação do dólar, a apreciação do real tem se mostrado significativa no período recente, mesmo quando se considera as moedas dos principais mercados externos de destino dos produtos brasileiros.

\section{GRÁFICO 1 - EVOLUÇÃO DA TAXA DE CÂMBIO REAL MULTILATERAL: JUL/1994-JUN/2008}

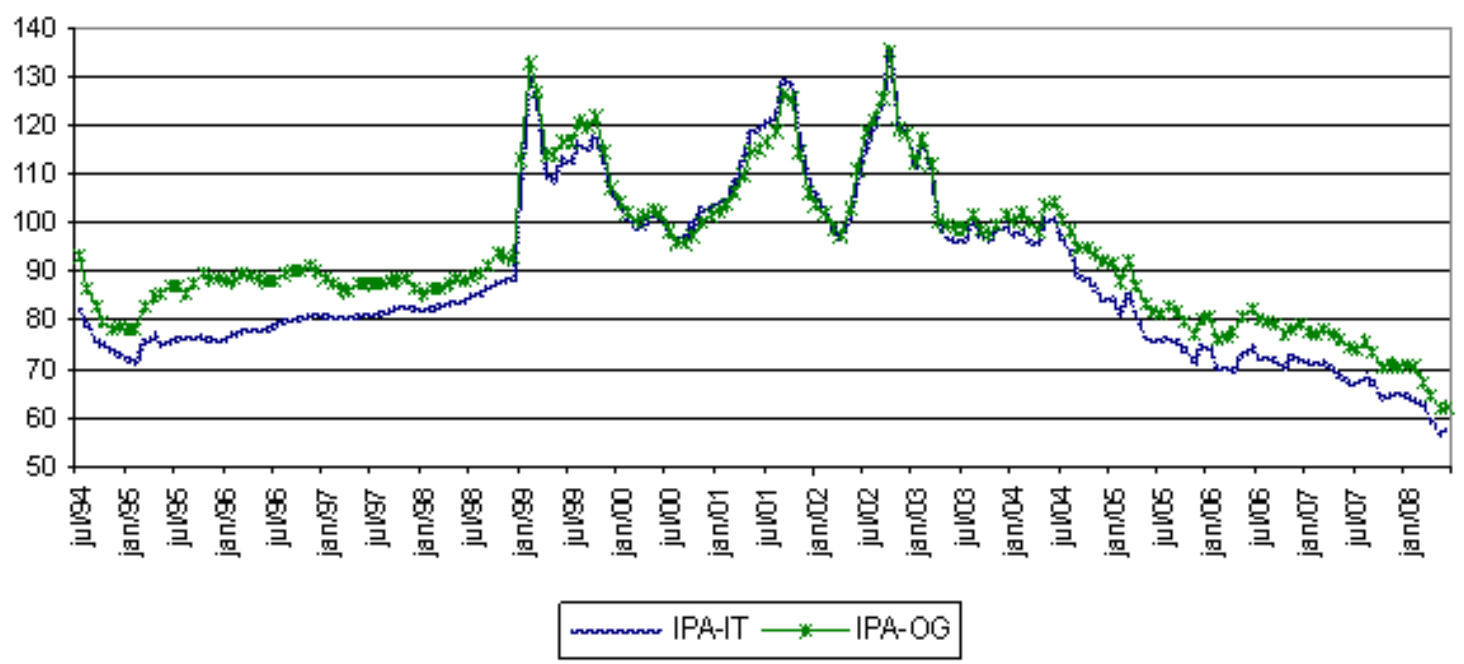

FONTE: Instituto de Pesquisa Econômica Aplicada (IPEA)

Muitos analistas já apontavam que o câmbio estava muito apreciado no começo do Plano Real. Atualmente, com o câmbio mais apreciado em termos reais e por um longo período, há uma tendência de mudanças na estrutura produtiva e na pauta de exportações.

As elevadas taxas de juros reais por um longo período de tempo, como pode ser visto pelo Gráfico 2, também tem impactos relevantes sobre a estrutura produtiva e, conseqüentemente, na pauta de exportações. O papel dos juros sobre os investimentos produtivos é bem difundido na literatura econômica e, conforme argumentando anteriormente, o impacto dos juros domésticos nos diversos setores e segmentos é diferenciado, pois alguns possuem maior facilidade na captação de recursos externos. 
GRÁFICO 2 - EVOLUÇÃO DA TAXA DE JUROS SELIC NOMINAL E REAL: JUL/1996-MAI/2008

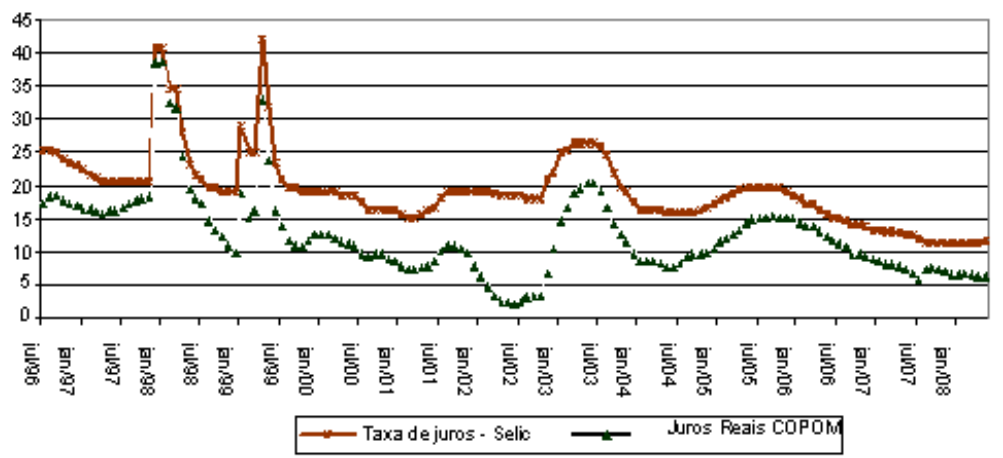

FONTE: Boletim do Banco Central do Brasil

Apesar da queda dos juros domésticos a partir do final de 2005 e da sua maior estabilidade, os juros da economia brasileira ainda são elevados, relativamente ao resto do mundo. Assim, o impacto dessa variável sobre setores e segmentos formados por empresas de pequeno e médio porte com dificuldades de acesso ao financiamento externo é relevante.

No Gráfico 3 é possível notar a variação na participação relativa das exportações dos setores da economia (média móvel dos últimos seis meses) quando estes são divididos de acordo com o grau de intensidade tecnológica em: 1) recursos naturais; 2) trabalho; 3) escala; 4) diferenciação; e 5) ciência. Apesar da grande variabilidade é considerável o aumento do valor das exportações dos bens baseados em recursos naturais e em escala.

\section{GRÁFICO 3 - EVOLUÇÃO DA PARTICIPAÇÃO DOS SETORES DIVIDIDOS DE ACORDO COM A INTENSIDADE TECNOLÓGICA NA PAUTA DE EXPORTAÇÃO BRASILEIRA (MÉDIA MÓVEL DOS ÚLTIMOS SEIS MESES): JUN/1996-FEV/2008}

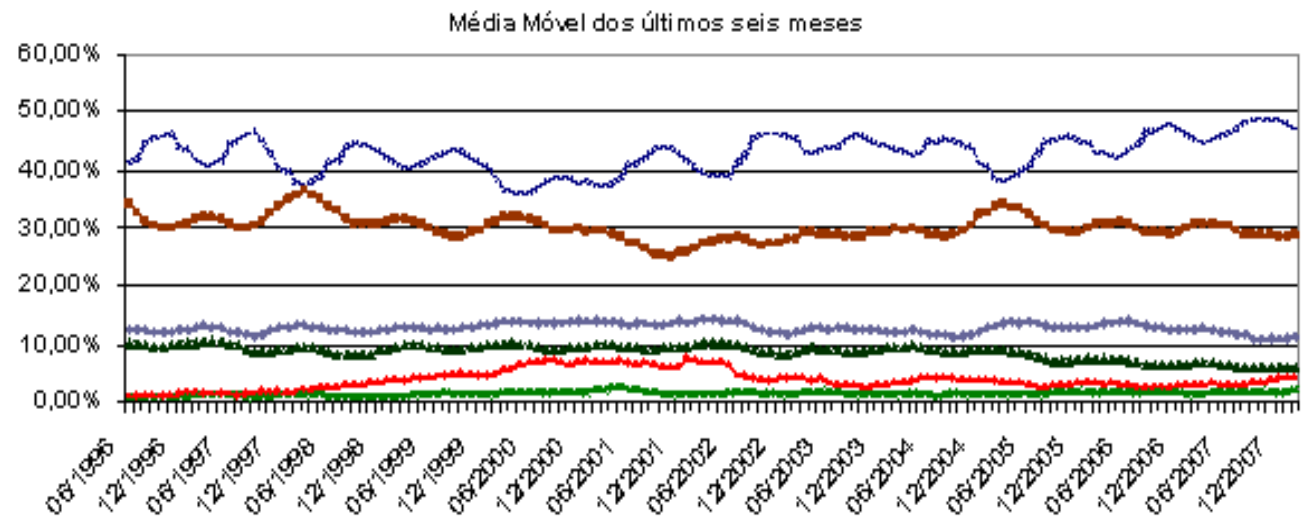

\begin{tabular}{|c|c|c|}
\hline mmnnmRiecurso Natural & —_Outros & $\begin{array}{l}\text { Intensiwo em trabalho } \\
\text { Baseado em ciência }\end{array}$ \\
\hline
\end{tabular}

FONTE: Ministério do Desenvolvimento, Indústria e Comércio Exterior - dados do Alice Web. 
De acordo com os dados apresentados no gráfico acima, é possível notar que as exportações de bens intensivos em recursos naturais passaram de $40 \%$ para quase $50 \%$ na pauta de exportações do país entre 1996 e 2008. Mesmo com os ciclos, é interessante notar que, a partir de 2005, os ciclos se tornaram menores em torno de uma média maior.

A média dos últimos seis meses da participação na pauta de exportações do setor intensivo em trabalho passou de 10,24\%, em junho de 1996, para 6,18\%, em fevereiro de 2008, o que representa uma queda de $40 \%$. Assim, os resultados mostram que o setor intensivo em trabalho foi o que mais sofreu nos anos recentes.

Ainda com os dados do Gráfico 3, é interessante notar o ganho de participação relativa das exportações baseadas em ciência, apesar da grande oscilação apresentada no período. A média da participação dos últimos seis meses desse setor passou de 1,06\%, em junho de 1996 para 4,20\%, em fevereiro de 2008, alternando um período de ganho de participação entre 1996 e 2000, seguido por uma queda ao final de 2002 e variações não muito significativas na sequência.

\subsection{ANÁLISE ECONOMÉTRICA}

Para se fazer uma análise mais formal da relação entre as variáveis acima destacadas, utilizou-se análise de regressão. A taxa de crescimento das exportações de cada um dos cinco segmentos foi considerada como variável dependente. As taxas de câmbio, juros e crescimento dos EUA e suas respectivas defasagens foram consideradas variáveis explicativas. Assim, a análise foi feita de acordo com cinco modelos diferentes, onde a mudança ocorre apenas na variável dependente.

Cabe ressaltar que a taxa de câmbio é uma variável crucial que afeta as expectativas e planejamento dos agentes envolvidos no setor exportador, que futuramente altera suas decisões de investimento. Assim, esse processo não é automático, ou seja, os consumidores levam tempo para perceber a mudança dos preços relativos, as empresa levam tempo para mudar de fornecedor, dentre outros motivos que podem resultar numa diferença razoável de tempo para que ocorra este ajuste. Desse modo, seria de se esperar certa defasagem entre alterações nesta e seus efeitos na economia. Os mesmos argumentos são válidos para a taxa de crescimento dos parceiros comerciais do Brasil e taxa doméstica de juros. 
Para incorporar a existência de defasagem dos impactos do câmbio e juros sobre a economia, foram utilizadas as respectivas defasagens na equação de regressão. Para definir o número de defasagens, a primeira regressão foi estimada com um número relativamente alto de defasagens para todas as variáveis explicativas (16 defasagens). A partir dos resultados dessa regressão, utilizou-se o critério de informação de Akaike para verificar se a especificação do modelo sofria uma melhora com a redução das defasagens. Esse procedimento foi mantido até se encontrar o menor valor desse critério de seleção.

$\mathrm{Na}$ primeira regressão, onde a variável dependente é a exportação dos bens baseados em recursos naturais (BRN), foi detectado o problemas de normalidade e heterocedasticidade. Portanto, foi feito uso do método dos mínimos quadrados iterativos com redistribuição de pesos (Iteratively Reweighted Least Squares). Esse método é indicado para correção de erros não normais causado por variáveis independentes com elevada leverage ${ }^{2}$ que levam a presença de outliers. Também foi detectado um problema de multicolinearidade entre as variáveis defasadas do crescimento dos EUA, mas não muito grave.

$\mathrm{Na}$ segunda regressão, em que se utiliza a taxa de crescimento das exportações dos bens baseados em trabalho (BT) como variável dependente, foi detectada autocorrelação dos resíduos. Para correção de tal problema foi utilizado o método iterativo de Prais-Wisten (PW) para correção de correlação de primeira ordem dos resíduos. Os mesmos problemas de autocorrelação foram encontrados na terceira e quarta regressão, onde as variáveis dependentes são as taxas de crescimento das exportações dos produtos baseados em escala (BE) e em diferenciação (BD). O mesmo procedimento foi utilizado para corrigir tal problema, o que reduziu a autocorrelação de maneira significativa. Adicionalmente, na regressão em que BE é a variável dependente, foi detectada a presença de multicolinearidade moderada entre as defasagens da taxa de crescimento dos EUA, diminuindo o nível de significância dos coeficientes destas.

Finalmente, na última - a taxa de crescimento das exportações dos bens baseado em ciência é variável dependente $(\mathrm{BC})$ - foram detectados problemas de autocorrelação, não normalidade dos resíduos e heterocedasticidade. Para contornar os problemas acima mencionados foi empregado o método de Prais-Wisten com erros robustos (PWR), com redução dos problemas acima mencionados.

${ }^{2}$ Variáveis com elevada leverage possuem observações com grandes distâncias do valor médio. 
Os resultados das cinco regressões se encontram na Tabela 1. Foram retiradas as defasagens com coeficientes não estatisticamente diferentes de zero para facilitar a visualização e interpretação dos resultados.

TABELA 1 - RESULTADOS DA ANÁLISE DE REGRESSÃO COM VARIÁVEIS DEFASADAS

\begin{tabular}{|c|c|c|c|c|c|}
\hline & BRN (IRLS) & BT (PW) & $\mathrm{BE}(\mathrm{PW})$ & BD (PW) & BC (PWR) \\
\hline Cons. & & & & & $\begin{array}{c}0.139 \\
(0.078)^{*}\end{array}$ \\
\hline Cres. EUA & & & $\begin{array}{c}21.144 \\
(11.929)^{*}\end{array}$ & & \\
\hline T. Juros & & & & $\begin{array}{l}-0.158 \\
(0.071)^{* *}\end{array}$ & \\
\hline Cres. EUA (-1) & & & & & $\begin{array}{c}-114.848 \\
(50.514)^{* *}\end{array}$ \\
\hline Cres. EUA (-3) & & & & & $\begin{array}{c}127.685 \\
(58.544)^{* *}\end{array}$ \\
\hline Cres. EUA (-4) & & & & & $\begin{array}{c}-97.915 \\
(36.340)^{* * *}\end{array}$ \\
\hline Cres. EUA (-6) & $\begin{array}{c}52.908 \\
(29.187)^{*}\end{array}$ & & $\begin{array}{c}44.771 \\
(26.407)^{*}\end{array}$ & & \\
\hline Cres. EUA (-7) & & $\begin{array}{l}-14.242 \\
(7.967)^{*}\end{array}$ & $\begin{array}{c}-44.778 \\
(26.318)^{*}\end{array}$ & $\begin{array}{c}-27.285 \\
(14.109)^{* *}\end{array}$ & \\
\hline Cres. EUA (-11) & $\begin{array}{c}51.565 \\
(25.268)^{* *}\end{array}$ & & & & \\
\hline Cres. EUA (-12) & $\begin{array}{c}-30.958 \\
(18.448)^{*}\end{array}$ & & & & \\
\hline Cres. EUA (-16) & & & $\begin{array}{c}-19.531 \\
(11.982)^{*}\end{array}$ & & \\
\hline T.Câmbio (-2) & & $\begin{array}{c}0.526 \\
(0.312)^{*}\end{array}$ & & & \\
\hline T.Câmbio (-3) & & $\begin{array}{c}-0.656 \\
(0.321)^{* *}\end{array}$ & & & $\begin{array}{c}2.678 \\
(1.473)^{*}\end{array}$ \\
\hline T.Câmbio (-4) & $\begin{array}{c}0.926 \\
(0.485)^{*}\end{array}$ & & & & $\begin{array}{c}-2.212 \\
(1.310)^{*}\end{array}$ \\
\hline T.Câmbio (-5) & $\begin{array}{c}-1.281 \\
(0.498)^{* *}\end{array}$ & & & $\begin{array}{c}-0.907 \\
(0.533)^{*}\end{array}$ & \\
\hline T.Câmbio (-7) & & & $\begin{array}{c}0.903 \\
(0.474)^{*}\end{array}$ & & \\
\hline T.Câmbio (-8) & $\begin{array}{c}-1.126 \\
(0.503)^{* *}\end{array}$ & $\begin{array}{c}-0.681 \\
(0.312)^{* *}\end{array}$ & $\begin{array}{c}-1.351 \\
(0.430)^{* * *}\end{array}$ & $\begin{array}{l}-0.878 \\
(0.525)^{*}\end{array}$ & \\
\hline T.Câmbio (-9) & & $\begin{array}{c}0.496 \\
(0.284)^{*}\end{array}$ & $\begin{array}{c}0.751 \\
(0.317)^{* *}\end{array}$ & & \\
\hline T.Câmbio (-10) & $\begin{array}{c}0.827 \\
(0.507)^{*}\end{array}$ & & & & \\
\hline T.Câmbio (-12) & & & & & $\begin{array}{c}2.482 \\
(1.257)^{* *}\end{array}$ \\
\hline T.Câmbio (-13) & & & & & $\begin{array}{c}-2.508 \\
(1.231)^{* *}\end{array}$ \\
\hline T.Juros (-4) & $\begin{array}{c}0.254 \\
(0.090)^{* * *}\end{array}$ & & & & \\
\hline T.Juros (-5) & 0197 & & & & $\begin{array}{c}0.368 \\
(0.191)^{*}\end{array}$ \\
\hline
\end{tabular}

20 

T. Juros (-7)
$(0.090)^{* *}$
$(0.090)^{*}$

T. Juros (-11)

T. Juros (-12)

T. Juros (-15)

0.183

T. Juros (-16)

$(0.091)^{* *}$

0.169

$(0.096)^{*}$

$\mathrm{R}^{2}$

0.36

0.18

0.25

$(0.059)^{* *}$
0.308

$(0.178)^{*}$

$-0.147$

$(0.072)^{* *}$

$-0.261$

$(0.128)^{* *}$

Notas: *** significativo ao nível de $1 \%$, ** significativo ao nível de $5 \%$, * significativo ao nível de $10 \%$. PW é o método de Prais-Wisten, IRLS é o de mínimos quadrados iterativos com redistribuição de pesos e PWR o de PraisWisten com erros robustos. As variáveis dependentes são BRN (taxa de variação das exportações dos bens baseados em recursos naturais), BT (taxa de variação das exportações dos bens baseados em trabalho), BE (taxa de variação das exportações dos produtos baseados em escala), BD (taxa de variação das exportações dos bens baseados em diferenciação) e BC (taxa de variação das exportações dos produtos baseados em ciência). As variáveis independentes são T. Câmbio (taxa de variação cambial) e T. Juros (taxa de variação dos juros Reais). Crês. EUA é a taxa real de crescimento dos Estados Unidos. Entre parênteses estão os valores calculados do desvio padrão dos parâmetros.

Como as variáveis estão em taxa de crescimento, os coeficientes representam o impacto das variações das mesmas. Ao observar o impacto do crescimento dos EUA como proxy para os crescimento mundial, é possível notar que o setor que obteve grande benefício nesse processo foi o intensivo em recursos naturais. Ao somar as estimativas de ponto, chega-se a conclusão que o aumento de 1\% na taxa de crescimento dos EUA provoca uma elevação de aproximadamente $70 \%$ na taxa de crescimento das exportações dos bens baseados em recursos naturais. A taxa de crescimento dos EUA teve um impacto negativo ou nulo nos demais setores.

Ao somar as estimativas de ponto dos coeficientes da taxa de câmbio da regressão onde a variável dependente é a taxa de crescimento das exportações dos bens baseados em recursos naturais $(\mathrm{RN})$, chega-se a um valor negativo. Desse modo, se o câmbio exerce algum impacto sobre essa variável, a relação é inversa, ou seja, uma variação da taxa de câmbio no sentido de apreciação estimula a taxa de crescimento das exportações baseadas em recursos naturais.

No entanto, o estudo da FIESP (2006) aponta que a relação de causalidade é inversa, ou seja, o aumento da demanda de commodities agrícolas no mercado internacional está levando a uma elevação no preço desses produtos. O Brasil, como grande produtor de algumas dessas commodities, vem experimentando uma grande elevação no volume de produtos exportados, o que intensifica o processo de valorização da taxa de câmbio.

Ao somar as estimativas de ponto da segunda regressão, o resultado é positivo, mas próximo de zero. Esse resultado indica que variações percentuais na taxa de câmbio não têm 
impacto significativo na taxa de crescimento das exportações dos bens baseados em trabalho, resultado que não seria esperado por ser um segmento que compete via preços.

As próximas três regressões indicam que variações na taxa de câmbio no sentido de apreciação afetam negativamente a taxa de crescimento das exportações dos bens baseados em escala, positivamente a taxa dos bens baseados em diferenciação e não possuem efeitos significativos na taxa de crescimento das exportações baseadas em ciência.

Já elevações na taxa de juros parecem ter efeitos negativos na taxa de crescimento das exportações dos bens baseados em escala e diferenciação. As taxas de crescimento das exportações dos bens baseados em recursos naturais e em ciência não foram influenciadas negativamente nos períodos em que a taxa de crescimento dos juros foi positiva. Os resultados mostram que existe uma correlação positiva na taxa de variação dessas duas variáveis.

O que fica claro dos resultados apresentados na Tabela 1 é que o segmento baseado em recursos naturais foi o que teve maior benefício do crescimento dos principais parceiros comerciais do Brasil (considerando a taxa de crescimento dos EUA como proxy). Adicionalmente, esse segmento não foi prejudicado pela valorização cambial e pela política de juros elevados. Neste caso, cabe ressaltar que para este segmento a valorização cambial foi relativamente compensada pelo aumento dos preços das commodities nos mercados internacionais.

GRÁFICO 4 - EVOLUÇÃO DA TAXA DE CÂMBIO E DO ÍNDICE DE PREÇO DAS COMMODITIES JAN./2002 A OUT./2006

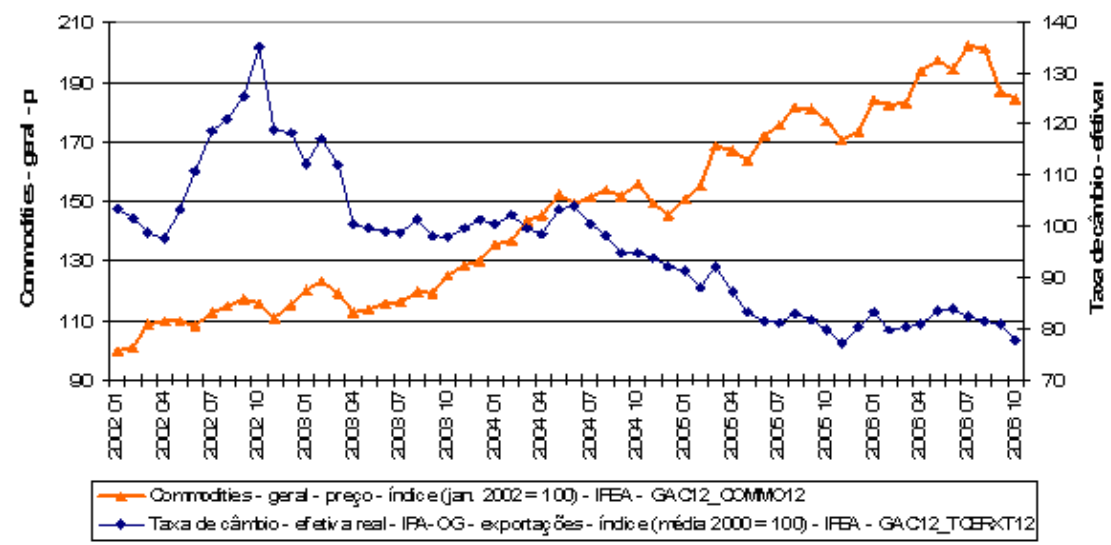

FONTE: IPEA (2007) apud IPEADATA (2007).

Já os resultados das exportações do segmento baseados em trabalho não esclarecem muito o fraco desempenho deste, no período de análise. Uma das possibilidades é que ao se trabalhar com taxas de crescimento das variáveis, informações relevantes de longo prazo são 
perdidas. De qualquer forma, esse segmento não vem sendo beneficiado pelas políticas macroeconômicas adotadas, nem pelo crescimento do resto do mundo.

A política de juros elevados prejudica os segmentos baseadas em escala e diferenciação, enquanto este ainda vem sofrendo com a apreciação da taxa de câmbio, além de não aproveitar a onda de crescimento da economia mundial.

Finalmente, as exportações do segmento baseado em ciência não estão enfrentando problemas com apreciações da taxa de câmbio e nem com elevações da taxa de juros, ajudando a explicar seu bom desempenho no período.

\section{CONCLUSÕES}

Os resultados apresentados indicam que os setores mais favorecidos pelo crescimento do comércio mundial e que não sofreram com a volatilidade das taxas de câmbio e juros ganharam participação no total das exportações brasileiras: bens baseados em recursos naturais e em ciência.

No entanto, é importante ressaltar que as exportações dos bens baseados em recursos naturais passaram de 40\% para quase 50\%, enquanto que as exportações baseadas em ciência passaram de 1,06\% para 4,20\%, considerando a média móvel dos últimos seis meses das duas variáveis, no período de junho de 1996 a fevereiro de 2008. Portanto, apesar do ganho de participação das exportações dos bens intensivos em ciência, a importância destes ainda é muito pequena em relação ao total das exportações.

Isso significa que o país está ficando mais dependente das exportações de bens baseados em recursos naturais devido ao crescimento da demanda mundial pelos mesmos. Como tais produtos não são dinâmicos do ponto de vista tecnológico e da elasticidade renda da demanda, considerando países de renda mais elevadas, tal mudança estrutural trará mudanças no dinamismo das exportações brasileiras com conseqüências negativas sobre seu crescimento econômico futuro.

Segmentos mais dinâmicos e com maiores capacidades de dinamizar as exportações brasileiras em um prazo mais longo de tempo, como o intensivo em escala e diferenciação, vêm perdendo participação: passaram de 34,03\% e 12,52\%, em junho de 1996, para 28,96\% e 11,31\%, em fevereiro de 2008, respectivamente. Além disso, o segmento mais importante na geração de 
empregos foi o que mais sofreu, passando de uma participação de 10,24\% para 6,18\% no período da análise.

\section{REFERÊNCIAS}

IPEADATA (2007). Séries históricas dos preços das commodities e da taxa real de câmbio, elaboradas pelo Instituto de Pesquisa Econômica Aplicada, IPEA. Disponível em www.ipeadata.gov.br. Acessado em 30 de março de 2007.

FEDERAÇÃO DAS INDÚSTRIAS DO ESTADO DE SÃO PAULO (FIESP). Desempenho das exportações, até quando vai o crescimento? Departamento de Pesquisas e Estudos Econômicos DEPECON, 20/09/2006, 2006.

MCCOMBIE, J.S.L., ROBERTS, M. The Role of the Balance of Payments in Economic Growth. In: The Economics of Demand Led Growth, Challenging the Supply-Side Vision of the Long-Run. Edited by Setterfield, M, p. 87-114, 2002.

PARK, H. M. Testing Normality in SAS, STATA, and SPSS. Site: http://pytheas.ucs.indiana.edu. Site acessado em 09/09/2006.

THIRLWALL, A.P. The Balance of Payments Constraint as a Explanation of International Growth Rate Differences. Banca Nazionale del Lavoro Quarterly Review, $\mathrm{n}^{\circ}$ 128, March, 1979. 